\title{
The study on Moisture Damage of the External Insulation Wall of Residential Buildings in Cold Area
}

\author{
Jiu-hong ZHANG ${ }^{1, a}$, Mei-xu FANG ${ }^{2, b}$, Jin $\mathrm{LI}^{3, c}$ \\ ${ }^{1}$ School of Architecture and Urban Planning, Shenyang Jianzhu University, Shenyang 100168 , \\ China

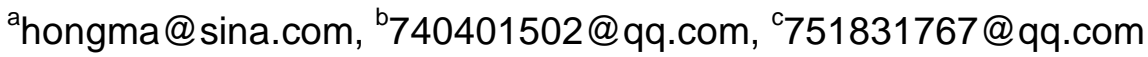

\begin{abstract}
Keywords: Severe cold area; Exterior insulation of external wall; Transfer of heat and moisture; Moisture damage
\end{abstract}

Abstract. Based on the steady state heat and moisture transfer theory, according to the characteristics of climate in sever cold area; they analyzed the heat and moisture state of brick and paint decoration wall of residential buildings in Shenyang area. The main reason for its failure is that the brick wall dampness design did not meet the design requirements. To the floated finish wall that heat and moisture meet the design requirements of the situation, the main reasons for the damage is unreasonable construction technology. In view of the residence building wall heat and moisture damage reason, they put forward corresponding countermeasures.

\section{Chinese library classification number : TU111}

In sever cold region, besides it is affected by temperature changes, internal condensation water of frost heave can also cause the surface crack and fall-off. For exterior-protected construction moisture-proof design of building with heating function should have to calculating the condensation of composite insulation wall inside, if do not conform to the requirements, the palisade structure moisture-proof measures should be taken.

\section{Exterior-protected construction heat and moisture transfer calculation method}

Exterior-protected construction heat transfer calculation method

In building construction, when the indoor and outdoor temperature range, in the outer wall and roof enclosure structure will have the phenomenon of heat transfer, heat is always a higher temperature to the side of the cooler side.

Internal temperature of the exterior-protected construction and the inner surface temperature is to measure and evaluate the important basis of palisade structure thermal performance. To test whether the inner surface and internal will produce the condensate or not and the influence of the inner surface temperature of indoor environment, all need to the design of exterior-protected construction internal accounting.

Exterior-protected construction moisture transfer calculation method

Water vapor permeability belongs to the migration of substances, and is often accompanied by the transformation of the form, either by vaporized into a liquid then into a solid (ice), and may reverse conversion, and again there is in the transformation of heat flow or temperature change and influence; but the transfer of heat transfer is energy. Therefore, the former is much more complicated than the latter. Simplify it with the perspective of application. If just discuss the exterior-protected construction under the condition of stable pure water vapor penetration process, the method is similar with that of stable heat transfer process. At present domestic moisture-proof design in architecture, adopt dew point temperature method and saturation vapor pressure curve/vapor pressure curve crossing method.

All water vapor condensation, a gas into a liquid, is necessarily environment or contact surface or object temperature below the dew point temperature. When the temperature of the water vapor partial pressure $\mathrm{P}$ more than with the saturated vapor pressure of water vapor Ps, namely the exterior-protected construction of the inner surface temperature is lower than the dew point 
temperature of the interior, the water vapor in the air will be liquefied separation, condensation phenomenon. So the inspection there is condensation is essentially its temperature is lower than the dew point temperature.

The selection of main heat and moisture parameter

(1) In order to ensure the personnel in the building indoor comfort, 《 the civil building heating ventilation and air conditioning design code》 GB50736-2012 rules: when designing heating, cold and winter cold area civil construction main room indoor design temperature from $18{ }^{\circ} \mathrm{C}$ to $24{ }^{\circ} \mathrm{C}$ should be adopted.

(2) due to the higher requirements ofllevel for comfortable, considering the relationship between the temperature and humidity, the range of relative humidity is $30 \% \sim 60 \%$.

(3) Outdoor heating calculation temperature is $-16.9^{\circ} \mathrm{C}$ in shenyang district. Air conditioning outdoor calculation relative humidity in winter is $60 \%$.According to the above principles and the actual situation, in this case, indoor temperature of the residential building are $18^{\circ} \mathrm{C}$ and $24^{\circ} \mathrm{C}$, relative humidity is $60 \%$; Outdoor temperature were set as $16.9^{\circ} \mathrm{C}$ and $-19^{\circ} \mathrm{C}$, relative humidity $60 \%$.

\section{Residential building external wall heat and moisture state analysis}

Current situation and problems of residential building external wall

The residential building whose surface is decorated with face brick.

Each residential building with 3 units, 6 floors and 3400 square meter was completed in 2010 .

The external thermal insulation composite insulation structure of residential buildings external wall use the lime-sand brick as the base wall, EPS insulation board as insulation and low steam permeability coefficient of face brick as layer of the external thermal insulation. The structure was shown in section Fig 1.

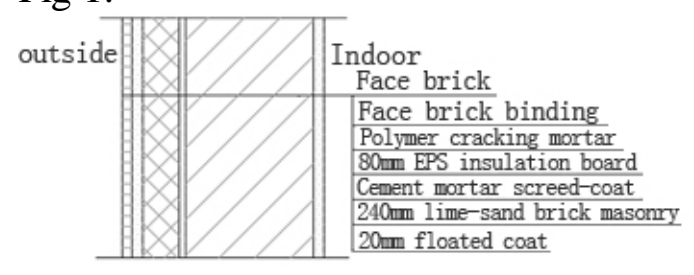

Fig. 1 The external thermal insulation composite insulation structure of brick decorated for the surface Table.1 Brick decorated residential building exterior wall construction material parameters

\begin{tabular}{ccccc}
\hline $\begin{array}{c}\text { numb } \\
\mathrm{er}\end{array}$ & $\begin{array}{c}\text { The name of the } \\
\text { material }\end{array}$ & $\mathrm{D}(\mathrm{mm})$ & $\lambda(\mathrm{W} / \mathrm{m} \cdot \mathrm{K})$ & $\begin{array}{c}\mathrm{H}-1 \mathrm{~g} /(\mathrm{m} \bullet \mathrm{h} \bullet \\
\mathrm{Pa})\end{array}$ \\
\hline 1 & face brick & 8 & 1.99 & 0.00000828 \\
2 & $\begin{array}{c}\text { adhesive mortar } \\
\text { EPS Thermal insulation } \\
\text { layer }\end{array}$ & 25 & 0.87 & 0.0000975 \\
& 80 & 0.041 & 0.0000162 \\
4 & $\begin{array}{c}\text { Cement mortar } \\
\text { screed-coat }\end{array}$ & 13 & 0.93 & 0.0000210 \\
5 & Lime-sand brick & 240 & 1.10 & 0.0001050 \\
6 & Cement mortar & 20 & 0.93 & 0.0000210 \\
\hline
\end{tabular}

Using the residential building for years, its brick layer bubbled cracks, exfoliation (see Fig.2), Following an on-site inspection and cutting glazed ceramic tile to inspect, we found that the mortar splicing glazed ceramic tile is humid, its moisture content is close to saturation, the breaking strength of Alkali resistant fiberglass cloth is obviously decreased in humid environment; there is no abnormal variations about the breaking strength in relatively dry environment. 


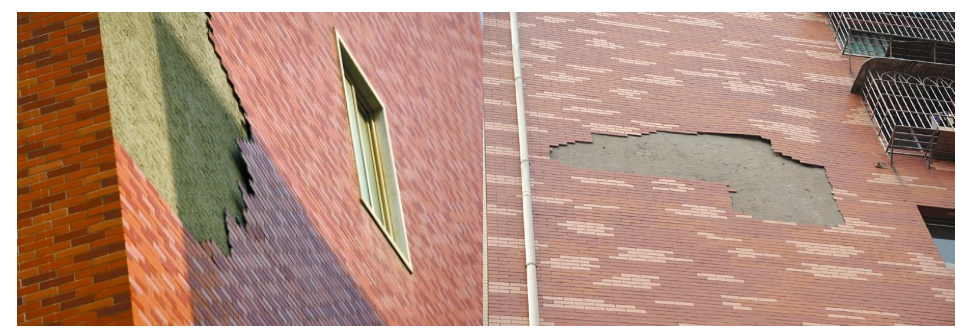

Fig. 2 Exterior wall brick falls off the status quo

The residential building whose surface is decorated with paint.

Each residential building with 5 units, 6 floors and 3400 square meter began construction in 2011 April, and put into service at the end of 10. the thermal insulation of exterior wall adopt the method that take EPS board as external insulation and brush the paint, thin plaster on the outside. The structure was shown in section Fig 3.

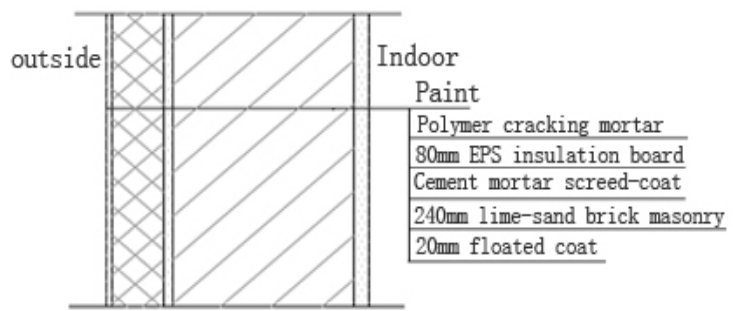

Fig. 3 EPS board and thin plastering paint is brushed outside

The paint off phenomenon of some residential building has emerged, but also occurred in the East and South, West and North seldom occurs; in the middle floor of multi-storey residential building, the phenomenon is more serious than both ends. Local shadow marks appear in the West and North. The Problems frequently appeared in March and April when the first heating period of the completion of the new project putting into use will be cut off, and the outdoor temperature exchange between positive and negative. Shedding appears in the insulating board and the insulating plate joint position or anchor position, exterior facing peel and exfoliate. Putty of Breakage has become powder and greatly reduced strength. After repaint the position, there is no shedding problem. The residential building where was not moved in the first year after its complement didn't have the problem.

Residential building external wall heat and moisture state analysis

According to calculation methods of Section 1.3, analyses and check the heat - moisture of exterior wall belonging to the residential building whose surface is decorated with face brick.Heat resistance in the inner surface and the outer surface of the exterior wall are $\mathrm{Ri} 0.11\left(\mathrm{~m}^{2} \cdot \mathrm{K} / \mathrm{W}\right)$ and $\mathrm{Re}$ $0.04\left(\mathrm{~m}^{2} \cdot \mathrm{K} / \mathrm{W}\right)$, by the way of seeking table. According to the parameters listed above formula and tables for the calculation, The wall heat transfer resistance $\mathrm{R}$ is $2.16\left(\mathrm{~m}^{2} \cdot \mathrm{K} / \mathrm{W}\right)$, the total resistance of exterior wall R0 is $2.31 \mathrm{~m}^{2} \cdot \mathrm{K} / \mathrm{W}$, heat transfer coefficient $\mathrm{K} 0$ is $0.43 \mathrm{~W} /\left(\mathrm{m}^{2} \cdot \mathrm{K}\right)$, meeting 《The Design Standard for Energy Efficiency of Residential Area Building in Severe Cold area and Cold area JGJ 26 $-2010 》$.

When the chamber was $18{ }^{\circ} \mathrm{C}$, the outdoor temperature is $-16.9^{\circ} \mathrm{Cor}-19^{\circ} \mathrm{C}$, checked the results about moisture state of residential exterior wall interior in table 2,3 and Fig.4,5. 
Table 2 Indoor $18{ }^{\circ} \mathrm{C},-16.9{ }^{\circ} \mathrm{C}$ outside wall internal temperature and vapor pressure gauge

\begin{tabular}{ccccc}
\hline Position & $\mathrm{T}\left({ }^{\circ} \mathrm{C}\right)$ & $\mathrm{PS}(\mathrm{Pa})$ & $\mathrm{P}(\mathrm{Pa})$ & $\mathrm{L}(\mathrm{mm})$ \\
\hline $\mathrm{ti}$ & 18 & 2062.5 & 1237.5 & \\
$\theta \mathrm{i}$ & 16.3 & 1851.8 & 1237.5 & 0 \\
$\theta 2$ & 16.0 & 1817.2 & 1188.5 & 20 \\
$\theta 3$ & 13.9 & 1587.9 & 406.7 & 260 \\
$\theta 4$ & 13.7 & 1566.5 & 400.3 & 273 \\
$\theta 5$ & -15.8 & 153.3 & 146.1 & 353 \\
$\theta 6$ & -16.2 & 149.3 & 132.9 & 378 \\
$\theta 7$ & -16.3 & 146.7 & 83.2 & 386 \\
$\mathrm{te}$ & -16.9 & 138.7 & 83.2 & \\
\hline
\end{tabular}

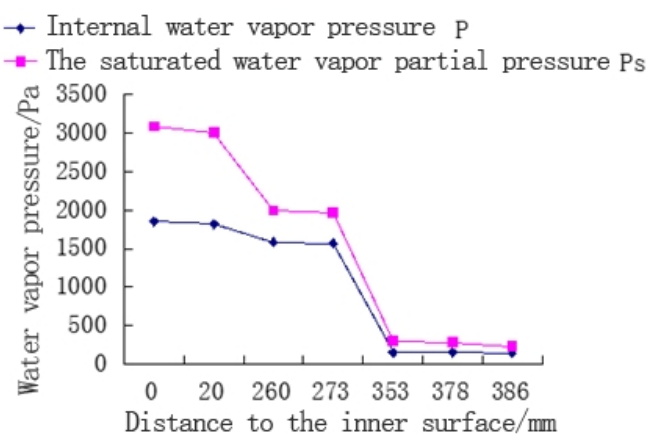

Fig. 4 Indoor $18{ }^{\circ} \mathrm{C},-16.9^{\circ} \mathrm{C}$ outside wall internal water vapor pressure $\mathrm{P}$ and the saturated water vapor partial pressure Ps diagram

Table 3 Indoor $18^{\circ} \mathrm{C},-19^{\circ}$ Coutdoor wall internal temperature and vapor pressure gauge

\begin{tabular}{ccccc}
\hline Position & $\mathrm{T}\left({ }^{\circ} \mathrm{C}\right)$ & $\mathrm{PS}(\mathrm{Pa})$ & $\mathrm{P}(\mathrm{Pa})$ & $\mathrm{L}(\mathrm{mm})$ \\
\hline $\mathrm{ti}$ & 18 & 2062.5 & 1237.5 & 0 \\
$\theta \mathrm{i}$ & 16.2 & 1841.2 & 1237.5 & 20 \\
$\theta 2$ & 15.9 & 1805.2 & 1187.8 & 260 \\
$\theta 3$ & 13.7 & 1566.5 & 395.7 & 273 \\
$\theta 4$ & 13.5 & 1546.5 & 389.3 & 353 \\
$\theta 5$ & -17.8 & 126.7 & 131.7 & 378 \\
$\theta 6$ & -18.3 & 149.3 & 118.4 & 386 \\
$\theta 7$ & -18.4 & 120 & 68.0 & \\
te & -19 & 113.3 & 68.0 & \\
\hline
\end{tabular}




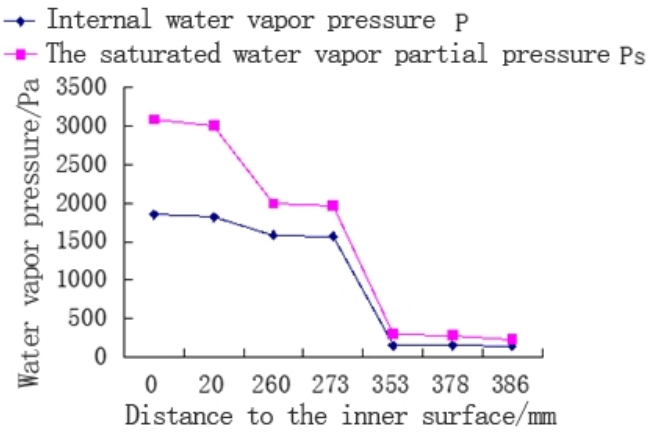

Fig. 5 Indoor $18^{\circ} \mathrm{C},-19^{\circ} \mathrm{C}$ outside wall internal water vapor pressure $\mathrm{P}$ and the saturated water vapor partial pressure Ps diagram

The above chart show that the temperature gradient is concentrated in the insulation layer, the temperature in the outer surface of the insulation layer declining sharply, make the surface easy to produce the phenomenon of condensation When the indoor and outdoor temperature are $18^{\circ} \mathrm{C}$ and $-16.9^{\circ} \mathrm{C}$, there isn't the phenomenon of internal condensation. When the indoor temperature is $18^{\circ} \mathrm{C}$, outdoor are $-19^{\circ} \mathrm{C}$, the outer surface of the insulating layer and the bonding layer surface water vapor pressure higher than the saturation vapor pressure of water at the same temperature, and the outdoor temperature is low, the condensation phenomenon will be more heavy.

The exterior wall structure project of the residential building whose surface is decorated with paint is that Brick instead of permeability coefficient of waterproof coating permeability in the project of the residential building whose surface is decorated with face brick. Under the condition of the remaining structure level remains unchanged, the total thermal resistance of the residential building whose surface is decorated with paint is calculated, the result R0 is $2.31 \mathrm{~m}^{2} \cdot \mathrm{K} / \mathrm{W}$, Heat transfer coefficient is $0.43 \mathrm{~W} /\left(\mathrm{m}^{2}, \mathrm{~K}\right)$. In the calculation of the most unfavorable conditions, namely $18{ }^{\circ} \mathrm{C}$ indoor, outdoor $-19{ }^{\circ} \mathrm{C}$, paint facing wall internal water vapor partial pressure also far less than with the temperature of saturated steam partial pressure.

\section{Residential building external wall heat and moisture damage reason and countermeasures}

moisture damage reason

The brick wall

Due to the brick has strong ability of self-cleaning, and durable, making brick get more extensive application in many residential buildings. But brick steam permeability coefficient is very small, about $40 \%$ of the cement mortar permeability, gas permeability is bad, easy to cause composite wall inside is difficult to discharge water vapor, thus accumulating condensate produced. By a hot wet state analysis of the external walls, the brick veneer wall wet design did not meet requirements of the wall inside the condensation phenomena, such as frost heave in brick act the role of surface appear Hollowing, peeling and cracking phenomenon.

Paint facing wall

In the process of research, found that some hot wet calculation conform to the requirements of the design of residential building external wall also came the problem of exterior wall coating fall off. On the basis of investigation and comparison and the analysis of the system, found that the paint falls off phenomenon is mainly caused by construction technology arrangement is not reasonable.

(1) Paste the insulation board wall body has the characteristics of high humidity. By the limitation of cold region climate, and the economic interests of the developer, and so on a series of factors, housing construction period generally is $6 \sim 7$ months, short time limit for a project, most projects have time limit, the phenomenon of multiple deadlines. Due to large wall wet and winter indoor humidity, water 
vapor flow by the wall to outdoor, makes the thermal insulation layer of humidity increase, thus speeding up the coating decorative surface of the drop.

(2)The arrangement of the thermal insulation layer construction and plaster mucilage is not reasonable. When the paste thermal insulation layer, meet with rainy days or after rain outside insulation plastering construction. Not heating insulation under the weight of the moisture content increased, at the same time, the smaller the permeability coefficient of plastering mortar, makes the thermal insulation layer of moisture is difficult to discharge. Indoor water vapor migration increased the weight of the insulation layer of moisture rate, more than the allowable values.

(3)The seam between the two insulation board is too big. Due to the thermal insulation layer seam uneven, makes the water vapor permeability to focus on a few seams, cause local damage surface.

Wet damage solution

For the cause of the above a certain residential area residential building wall thermal wet damage, the following countermeasures are put forward :

(1) Design Company should strictly control the hot wet design depth of the composite wall, wall heat design meet the requirements of the specification to ensure the feasibility of construction scheme.

(2) when using the method of brick veneer, moisture-proof measures should be taken to structure, set up the steam trap layer or exhaust channel, so as to avoid internal water vapor because the wall not to go out, cause condensation phenomenon within the walls. Should choose good permeability, strength, weather resistance and other indicators meet the requirements of raw materials, used as a paint facing wall putty and coatings。

(3) The paste before the thermal insulation layer, should look at the base course in the smear permeability coefficient of the leveling layer, thereby increasing the wall penetration of the steam resistance, make indoor thermal insulation, not easy to permeate water vapor to reduce the internal water vapor partial pressure, in addition, can enhance the heat preservation plate bonding strength.

(4)In order to avoid the influence on the thermal insulation material of rain, should be under the condition of the primary drying, paste insulation board, and avoid of plastering mortar in rainy days or after rain, so as not to increase the weight of the insulation layer.

(5)when installing insulation board, should avoid excessive joint. When cannot avoid, should carry on the processing, to prevent water vapor concentration seepage problems.

(6) If the must be completed in the use of engineering, can finish without construction completion inspection and acceptance, wait until next year when the outdoor temperature reached construction conditions and then to act the role of the construction.

There are several factors of thermal and moisture damage wall. Indices such as permeability and strength and weathering of the raw materials do not conform to the requirements, the construction technology arrangement is inappropriate, in the process of building use, indoor temperature and humidity is high, and the wall design depth of thermal and moisture damage etc. These factors can cause the wall, so should from the architectural design, construction and use of each stage take feasible measures to prevent heat damage.

\section{Conclusions}

Analysis of the residential building brick veneer wall and paint facing wall of damp and hot state , obtain that the wet design of a brick veneer wall did not meet the design requirements, is the main cause of their damage. Paint facing the wall under the condition of the hot wet comply with the design requirements, have appeared in the hot wet damage phenomenon. Through the analysis, it is concluded that the damage is the main reason of the construction technology of arrangement is not reasonable.

The factor of Wall heat damage is various, involved in the initial structure design, selection of raw materials, the arrangement of the construction technology and construction in the process of using the entire life cycle. Should from the architectural design, construction, and the stages of use to avoid damage of heat and moisture. 


\section{Acknowledgements}

This work was financially supported by the National Natural Science Foundation of China(51278311), excellent talent cultivation fund of Liaoning Province(2014020071).

\section{References}

[1] He Jinchun. Research on moisture transferring in the Exterior thermal insulation composite wall in cold zone [J]. Xi'an: Xi'an University of Architecture and Technology, 2008.

[2]Zhao Lihua, Dong Zhongcheng, Jia Chunxia. Moisture through external insulation wall [J]. Journal of Harbin university of architecture, 2001 (6): 78-81.

[3]Chen Yongcheng, Chen Qigao. Research on humidity calculation method Building wall wet area [J]. Journal of chongqing construction university, 1997, 19 (3): 16-22.

[4] Mendes N, Ridley I, Lamberts R. PC program for the prediction of heat and moisture transfer in porous building elements [C]. Proceedings of the Sixth International IBPSA Conference, 1999:

277-283.

[5]Special meteorological data sets of China building thermal environment analysis. Beijing: China building industry press, 2005.

[6]Jia Chunxia, Zhao Lihua, Dong Zhongcheng. Research on Moisture through composite wall Outside of polystyrene in Cold region [J]. Journal of thermal insulation materials and energy-saving building, 2001 (8): 16-19.

[7]Wang Jiachun, Yan Peiyu, Han Jianguo, etc. On the wall the influence of exterior insulation system dewing [J]. New building materials, 2004 (1): 51-53.

[8]Zhang Liaoyuan. Numerical simulation of heat and moisture transport in the construction of building external walls [J]. Beijing: Beijing jiaotong university, 2006.

[9] Shenyang residential building energy efficiency design standards. DB2101 J01-2006.

[10]Zhujie. Research on phase change heat and mass transfer process in porous media [J]. Dalian:

Dalian university of technology, 2006. 